PII S0016-7037(00)00780-3

\title{
Temperature dependence of goethite dissolution promoted by trihydroxamate siderophores
}

\author{
Claudio Cocozza, ${ }^{1}$ Calvin C. G. Tsao, ${ }^{2}$ Sing-Foong Cheah, ${ }^{2}$ Stephan M. Kraemer, ${ }^{3}$ Kenneth N. Raymond, ${ }^{4}$ \\ Teodoro M. Miano, ${ }^{1}$ and Garrison Sposito ${ }^{2, *}$ \\ ${ }^{1}$ Dipartimento di Biologia e Chimica Agro-Forestale e Ambientale, Universitá degli Studi di Bari, 70126 Bari, Italy \\ ${ }^{2}$ Division of Ecosystem Sciences, University of California, Berkeley, CA 94720-3110, USA \\ ${ }^{3}$ Institute of Terrestrial Ecology, ETH-Zürich, CH-8952, Schlieren, Switzerland \\ ${ }^{4}$ Department of Chemistry, University of California, Berkeley, CA 94720-1460, USA \\ (Received February 8, 2001; accepted in revised form July 13, 2001)
}

\begin{abstract}
This article reports an investigation of the temperature dependence of goethite dissolution kinetics in the presence of desferrioxamine B (DFO-B), a trihydroxamate siderophore, and its acetyl derivative, desferrioxamine D1 (DFO-D1). At 25 and $40^{\circ} \mathrm{C}$, DFO-D1 dissolved goethite at twice the rate of DFO-B, whereas at $55^{\circ} \mathrm{C}$, the behavior of the two ligands was almost the same. Increasing the temperature from 25 to $55^{\circ} \mathrm{C}$ caused little or no significant change in DFO-B or DFO-D1 adsorption by goethite. A pseudo-first-order rate coefficient for dissolution, calculated as the ratio of the mass-normalized dissolution rate coefficient to the surface excess of siderophore, was approximately the same at 25 and $40^{\circ} \mathrm{C}$ for both siderophores. At $55^{\circ} \mathrm{C}$, however, this rate coefficient for DFO-D1 was about half that for DFO-B. Analysis of the temperature dependence of the mass-normalized dissolution rate coefficient via the Arrhenius equation led to an apparent activation energy that was larger for DFO-B than for DFO-D1, but much smaller than that reported for the proton-promoted dissolution of goethite. A compensation law was found to relate the pre-exponential factor to the apparent activation energy in the Arrhenius equation, in agreement with what has been noted for the proton-promoted dissolution of oxide minerals and for the complexation of $\mathrm{Fe}^{3+}$ by DFO-B and simple hydroxamate ligands in aqueous solution. Analysis of these results suggested that the siderophores adsorb on goethite with a only single hydroxamate group in bidentate ligation with an Fe(III) center. Copyright (C) 2002 Elsevier Science Ltd
\end{abstract}

\section{INTRODUCTION}

The importance of microbial siderophores [ $\sigma i \delta \eta \rho o s$ (iron) + $\phi \varepsilon ́ \rho \omega$ (carry)] in mineral weathering reactions has long been recognized (see, e.g., Cornell and Schwertmann, 1996), but it is only very recently that the geochemistry of these Fe(III)-specific ligands has been investigated quantitatively. Kalinowski et al. (2000) catalogued the few available data on siderophorepromoted mineral dissolution kinetics, noting a relatively modest rate enhancement by siderophores over proton-promoted dissolution under the same conditions. They noted also that a saturation effect exists when dissolution rates are measured as a function of increasing siderophore concentration, which supports the concept of Stumm et al. (1987), that surface complexation of a ligand is a precursor to ligand-promoted mineral dissolution.

Most geochemical studies of siderophore-promoted mineral dissolution have utilized the common trihydroxamate siderophore, desferrioxamine B (DFO-B, Fig. 1), which possesses three hydroxamate functional groups, each comprising a carbonyl adjacent to a hydroxylamine. The aqueous solution chemistry of this siderophore has been investigated extensively, with a number of its thermodynamics and kinetic parameters now reported (Biruš et al., 1988; Crumbliss, 1991; AlbrechtGary and Crumbliss, 1998). Analyzing their experiments on the DFO-promoted dissolution kinetics of goethite $(\alpha-\mathrm{FeOOH})$, Kraemer et al. (1999) drew on this kind of information to speculate that the three hydroxamate groups in DFO-B might

* Author to whom correspondence should be addressed (gsposito@ nature.berkeley.edu). coordinate to surface Fe(III) centers independently while promoting dissolution. Liermann et al. (2000) observed an approximately square-root dependence on DFO-B concentration for the Fe release rate from hornblende, leading them to conclude that DFO-B adsorption is necessary to mineral dissolution. Holmén and Casey $(1996,1998)$ and Holmén et al. (1997) have added mechanistic details to this picture in their careful investigations of the dissolution of goethite promoted by acetohydroxamic acid $\left[\mathrm{CH}_{3} \mathrm{COHNOH}\right.$, aHA], a simple monohydroxamate ligand. They concluded that the aHA hydroxamate group coordinates to a surface Fe(III) center on the mineral in much the same way as in aqueous solution (i.e., bidentate ligation), but does so with the greater impact of vicinal atoms in the mineral, as compared with solvating water molecules in aqueous solution, on the distribution of electron density within the surface complex.

All previous studies of siderophore-promoted dissolution have been performed at ambient temperature. In this article, we report the first investigation of the temperature dependence of both ligand adsorption and mineral dissolution kinetics for goethite in the presence of the two important hydroxamate siderophores, DFO-B and DFO-D1 (Fig. 1), the latter of which is an uncharged acetyl derivative of DFO-B (van der Helm et al., 1987). The objectives of our research were to determine quantitatively the effect of increasing temperature on the processes underlying goethite weathering by trihydroxamate siderophores and to elucidate further the mechanisms of siderophore-promoted goethite dissolution through an analysis of temperature-dependent kinetics along conventional geochemical lines (Lasaga, 1998), while informed by comparable data 
<smiles>CC(=O)NCN(O)C(=O)CC(=O)NCN(O)C(=O)CC(=O)NCCN(O)C(C)=O</smiles><smiles>[H][Y]([H])([O-])CN(O)C(=O)CC(=O)NCN(O)C(=O)CC(=O)NCN(O)C(C)=O</smiles>

Fig. 1. Molecular structures of (a) DFO-D1 and (b) DFO-B.

for the aqueous solution reactions of DFO-B (Biruš et al., 1988; Crumbliss, 1991).

\section{MATERIALS AND METHODS}

\subsection{Materials}

Goethite was synthesized following the method of Schwertmann and Cornell (1991). Briefly, $180 \mathrm{~mL}$ of $5 \mathrm{~mol} / \mathrm{L} \mathrm{KOH}$ solution was added rapidly with stirring to $100 \mathrm{~mL}$ of $1 \mathrm{~mol} / \mathrm{L} \mathrm{Fe}\left(\mathrm{NO}_{3}\right)_{3}$ solution in a 2-L polyethylene flask. The resulting suspension was then brought to a 2-L total volume with high-purity $18 \mathrm{M} \Omega \mathrm{cm}^{-1}$ water (Milli-Q Plus, Millipore) and heated at $70^{\circ} \mathrm{C}$ for $60 \mathrm{~h}$. Next, the precipitated product was centrifuged, washed with high-purity water, and freeze-dried. Powder X-ray diffraction and Fourier transform infrared spectroscopy confirmed that the synthesized solid was indeed goethite. The specific surface area of the sample was not determined but should be similar to that of the goethite sample prepared in identical fashion by Kraemer et al. (1999), $35 \pm 3 \mathrm{~m}^{2} / \mathrm{g}$.

The sample of DFO-B used was the mesylate salt $\left[\mathrm{C}_{25} \mathrm{H}_{46}\right.$ $\mathrm{N}_{5} \mathrm{O}_{8} \mathrm{NH}_{3}^{+}\left(\mathrm{CH}_{3} \mathrm{SO}_{3}^{-}\right)$] produced by Ciba-Geigy (Desferal) and received as a gift from the Salutar Corporation. The sample of DFO-D1 $\left(\mathrm{C}_{27} \mathrm{H}_{50} \mathrm{~N}_{6} \mathrm{O}_{9}\right)$ used was prepared from DFO-B by peracetylation in methanol as described by Kraemer et al. (1999).

\subsection{Dissolution Experiments}

Goethite dissolution kinetics were measured at $\mathrm{pH} 6.5$ in batch reactors open to the atmosphere. The $\mathrm{pH}$ value was selected to ensure negligible proton- or hydroxide ion-promoted dissolution and particle coagulation during the $350-\mathrm{h}$ reaction period. The solids concentration was $0.5 \mathrm{~g} / \mathrm{L}$ at 25 and $40^{\circ} \mathrm{C} ; 0.1 \mathrm{~g} / \mathrm{L}$ was used at $55^{\circ} \mathrm{C}$. The lower solids concentration was selected so as to maintain far-from-equilibrium conditions throughout the dissolution experiment, given the expected high dissolution rate at $55^{\circ} \mathrm{C}$. The background electrolyte solution was $0.01 \mathrm{~mol} / \mathrm{L} \mathrm{NaClO}{ }_{4}$ mixed with $5 \mathrm{mM}$ MOPS pH buffer $\left(\mathrm{C}_{7} \mathrm{H}_{15} \mathrm{NSO}_{4}\right)$, a weakly complexing tertiary amine (Yu et al., 1997).

In each dissolution experiment, goethite was placed in wide-mouthed polypropylene bottles wrapped with $\mathrm{Al}$ foil and suspended in the background electrolyte solution by ultrasonication for $1 \mathrm{~min}$. Then DFO-B or DFO-D1 solution was added to achieve an initial concentration of $240 \mu \mathrm{M}$, and $\mathrm{pH}$ was adjusted to 6.5 with $0.1 \mathrm{~mol} / \mathrm{L} \mathrm{NaOH}$ or $\mathrm{HClO}_{4}$. Background electrolyte solution was added to make the total sample mass $200 \mathrm{~g}$. Sample stirring was accomplished by floating stir bars, and constant temperature $\left( \pm 1^{\circ} \mathrm{C}\right)$ was maintained by immersion in a thermally controlled water bath. Aliquots taken periodically over $350 \mathrm{~h}$ reaction time were filtered with $0.05-\mu \mathrm{m}$ syringe filters (MFMillipore). The first $3 \mathrm{~mL}$ of filtrate was discarded; the second $5 \mathrm{~mL}$ was retained for $\mathrm{pH}$ measurement, and $10 \mathrm{~mL}$ of filtrate was acidified to approximately $\mathrm{pH} 1.5$ with concentrated perchloric acid. This last aliquot was stored under refrigeration for no more than 1 week before $\mathrm{Fe}$ analysis with a Thermal Jarrel-Ash ICP-AES unit reading emission at $238.2 \mathrm{~nm}$.

\subsection{Adsorption Experiments}

Adsorption of DFO-B and DFO-D1 on goethite was measured in batch reactors, open to the atmosphere, at the high solids concentration of $20 \mathrm{~g} / \mathrm{L}$, selected because DFO-B and DFO-D1 adsorption on goethite is relatively low at submillimolar initial concentrations (Kraemer et al., 1999). Because far-from-equilibrium ligand-promoted dissolution rates are expected to increase with the surface excess of the ligand (Stumm et al., 1987), a disadvantage of this arrangement is significant Fe release and a concomitant decrease in free siderophore concentration, necessitating a short reaction time. On the other hand, a short reaction time is consistent with measuring the rapid component of ligand adsorption, free from the effects of the subsequent slow detachment of Fe(III)ligand complexes into aqueous solution. Preliminary adsorption kinetics experiments involving 30,60,180, and 300 min reaction time (data not shown) indicated that the DFO-B adsorption rate dropped sharply after $60 \mathrm{~min}$ and therefore that $60 \mathrm{~min}$ was an optimal reaction period to achieve adsorption without significant dissolution.

Adsorption was investigated at $\mathrm{pH} 6.5$ in $0.01 \mathrm{~mol} / \mathrm{L} \mathrm{NaClO}_{4}$ solution that contained $5 \mathrm{mM}$ MOPS buffer. All samples were prepared in duplicate. Blanks (i.e., samples without goethite) were prepared to investigate adsorption to container walls and filters. In these batch studies, goethite and background electrolyte with buffer were placed in $30 \mathrm{~mL}$ amber HDPE bottles wrapped with Al foil. Predetermined amounts of $1 \mathrm{~mol} / \mathrm{L} \mathrm{NaOH}$ were added to reach the desired $\mathrm{pH}$ value. The sample bottle was filled with electrolyte solution to a final mass of $20 \mathrm{~g}$ and placed in a temperature-controlled water bath at 25,40 , or $55^{\circ} \mathrm{C}$. Then DFO-B or DFO-D1 stock solution was added to give an initial concentration of $300 \mu \mathrm{M}$.

For each siderophore at each reaction temperature, aliquots were taken from the duplicate samples and blanks, then filtered through $0.05-\mu \mathrm{m}$ Millipore membrane filters. A 3-mL portion from each filtrate was used for $\mathrm{pH}$ measurement. The remaining filtrate was separated into two 5-mL aliquots that were acidified to $\mathrm{pH} 1.5$ to 1.7 with concentrated perchloric acid. One aliquot of each pair then received $167 \mu \mathrm{L}$ of $\mathrm{Fe}\left(\mathrm{ClO}_{4}\right)_{3}$ stock solution $\left(15 \mathrm{mM}\right.$ or $18 \mathrm{mM} \mathrm{Fe}\left(\mathrm{ClO}_{4}\right)_{3}$ for DFO-B or DFO-D1, respectively).

Aliquots from the adsorption experiments were analyzed for siderophore concentration following the $\mathrm{Fe}$ (III) chelometric method of Solinas (1994), but with solid-phase separation by filtration instead of centrifugation. The absorbance of all sample and blank filtrates, both with and without added $\mathrm{Fe}$, was measured at $441 \mathrm{~nm}$ (DFO-B) or 474.5 $\mathrm{nm}$ (DFO-D1). The net absorbance of the blank-corrected sample aliquot to which $\mathrm{Fe}$ stock solution had been added was attributed to the concentration of siderophore not adsorbed. The surface excess of siderophore $(\mu \mathrm{mol} / \mathrm{g})$ was then calculated on dividing the corresponding concentration loss ( $300 \mu \mathrm{M}$ minus the sample concentration) by the solids concentration. The net absorbance of the blank-corrected sample aliquot to which $\mathrm{Fe}$ stock solution had not been added was used to monitor Fe released by goethite dissolution during the adsorption reaction. The concentration of dissolved Fe released after the 1-h adsorption experiment increased monotonically with temperature, averaging 2.5, 36, and $109 \mu \mathrm{M}$ for DFO-B and 20, 21, and $49 \mu \mathrm{M}$ for DFO-D 1 at 25,40 , and $55^{\circ} \mathrm{C}$, respectively.

Standards for the absorbance measurements were prepared by adding $1 \mathrm{~mL}$ Fe stock solution to solutions of $0,60,120,180,240$, and $300 \mu \mathrm{M}$ siderophore in $0.01 \mathrm{~mol} / \mathrm{L} \mathrm{NaClO}_{4}$ and acidifying to $\mathrm{pH} 1.5$ with $\mathrm{HClO}_{4}$. Absorbance was read on a Shimadzu UV 160 spectrophotometer with baseline correction. Proton activity was measured with a Ross combination electrode calibrated at $\mathrm{pH} 4.0,7.0$, and 10.0, with temperature correction.

\section{RESULTS}

Figures 2 and 3 show Fe release kinetics for goethite in the presence of the two siderophores at $240 \mu \mathrm{M}$ initial concentration. As observed also by Holmén and Casey (1996) for aHA, $\mathrm{Fe}$ release after $50 \mathrm{~h}$ followed zero-order kinetics, and the $\mathrm{Fe}$ concentrations depended linearly on time (Table 1), which is typical for dissolution reactions under far-from-equilibrium conditions (Stumm et al., 1987; Sposito, 1994; Lasaga, 1998). 


\section{DFO-B}

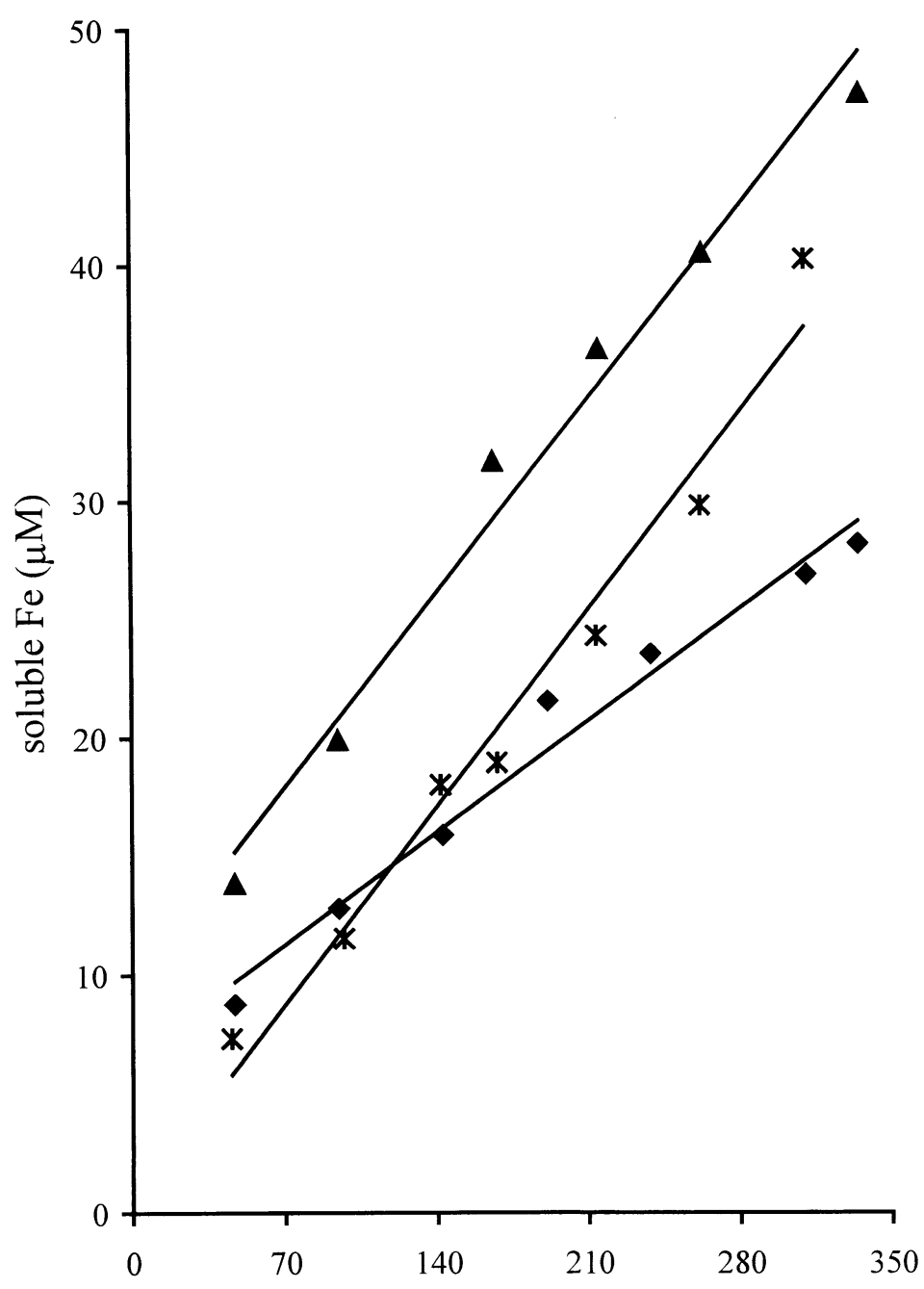

\section{time (h)}

Fig. 2. Iron release by goethite in presence of DFO-B at $25^{\circ} \mathrm{C}$ (diamonds), $40^{\circ} \mathrm{C}$ (triangles), and $55^{\circ} \mathrm{C}$ (asterisks). The lines through the data are linear regressions (Table 1). Initial siderophore concentration: $240 \mu \mathrm{M}$; solid concentration: 0.5 $\mathrm{g} / \mathrm{L}$ at 25 and $40^{\circ} \mathrm{C}, 0.1 \mathrm{~g} / \mathrm{L}$ at $55^{\circ} \mathrm{C} ; \mathrm{pH} 6.5$

The zero-order rate coefficient for Fe release is then equal to the slope of the regression-line equations in column 3 of Table 1. Increasing the temperature from 25 to $40^{\circ} \mathrm{C}$ caused a significant $(p=0.05)$ increase in the slopes of the linear fits for both siderophores. The same was not true for increasing temperature from 40 to $55^{\circ} \mathrm{C}$, but this is an effect of the much lower solids concentration used at the higher temperature. It is notable that Fe release in the presence of DFO-D1 was greater than that in the presence of DFO-B at 25 and $40^{\circ} \mathrm{C}$, whereas at $55^{\circ} \mathrm{C}$, it was the same for both siderophores within experimental precision.

The zero-order rate coefficient for dissolution reactions far from equilibrium is commonly assumed to be proportional to either the mass or the specific surface area of the dissolving solid (Zinder et al., 1986; Stumm et al., 1987; Lasaga, 1998). Brantley and Chen (1995) have reviewed the problematic issue of surface area normalization of mineral dissolution rates, leading us to choose mass normalization instead. Thus, a massnormalized rate coefficient for dissolution $\left(\mu \mathrm{mol} \mathrm{g} \mathrm{g}^{-1} \mathrm{~h}^{-1}\right)$ was calculated as the slope of the Fe release curve (Figs. 2 and 3) divided by the solids concentration. Values of the rate coefficient computed in this way are listed in the fourth column of Table 1. At 25 and $40^{\circ} \mathrm{C}$, this dissolution rate coefficient is about twice as large for DFO-D1 as for DFO-B, whereas at $55^{\circ} \mathrm{C}$, it is the same for both siderophores. For DFO-B, the rate coefficient is five times larger at $55^{\circ} \mathrm{C}$ than at $40^{\circ} \mathrm{C}$. The mass-normalized dissolution rate coefficient for DFO-D1 ap- 


\section{DFO-D1}

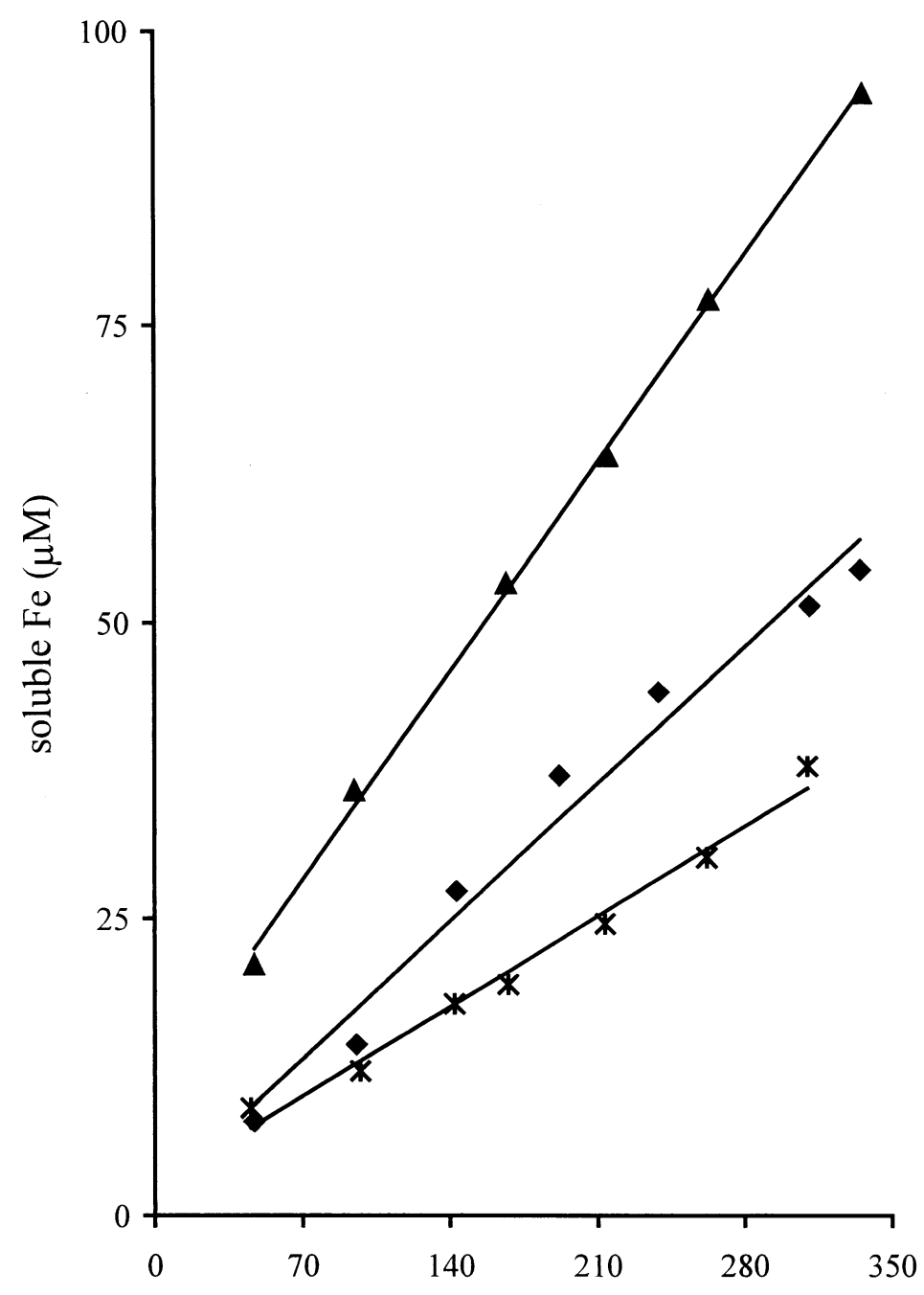

time (h)

Fig. 3. Iron release by goethite in presence of DFO-D1 at $25^{\circ} \mathrm{C}$ (diamonds), $40^{\circ} \mathrm{C}$ (triangles), and $55^{\circ} \mathrm{C}$ (asterisks). The lines through the data are linear regressions (Table 1). Initial siderophore concentration: $240 \mu \mathrm{M}$; solid concentration: 0.5 $\mathrm{g} / \mathrm{L}$ at 25 and $40^{\circ} \mathrm{C}, 0.1 \mathrm{~g} / \mathrm{L}$ at $55^{\circ} \mathrm{C} ; \mathrm{pH} 6.5$.

proximately doubles for every $15^{\circ} \mathrm{C}$ increase in temperature between 25 and $55^{\circ} \mathrm{C}$, whereas that for DFO-B exhibits this behavior only between 25 and $40^{\circ} \mathrm{C}$.

Kraemer et al. (1999) reported mass-normalized dissolution rates for goethite dissolution in the presence of DFO-B or DFO-D 1 at $25^{\circ} \mathrm{C}$ that are substantially smaller than the values given in Table 1. Although their experimental conditions were the same as used in the present study, their sample of goethite was not. Cornell and Schwertmann (1996) have noted that large differences exist among the proton-promoted dissolution rates published for goethite, which vary over orders of magnitude without correlation to specific surface area, crystallite length, or isomorphic substitution. They cite as the likely cause of this variability the strong influence of crystallite morphology, which changes substantially with conditions of mineral formation and pretreatment. Similarly, Eick et al. (1999) reported oxalate-promoted dissolution rates for goethite that were an order of magnitude smaller than those reported by Zinder et al. (1986) under the same reactor experimental conditions. Eick et al. (1999) noted that their goethite sample was freeze-dried after preparation and used without preconditioning, whereas that of Zinder et al. (1986) was pretreated in HF and preconditioned in oxalate solution for $3 \mathrm{~d}$.

Table 2 lists values of the surface excess of DFO-B and DFO-D1 at 25,40 , and $55^{\circ} \mathrm{C}$ on goethite at $\mathrm{pH} 6.5$ and $300 \mu \mathrm{M}$ initial siderophore concentration. The supernatant solution sid- 
Table 1. Linear regression equations and mass-normalized zero-order dissolution rate coefficient based on the Fe release data in Figs. 2 and 3.

\begin{tabular}{lccc} 
& & Regression equation ${ }^{\mathrm{b}}$ & $\begin{array}{c}\text { Rate coefficient } \\
(\mu \mathrm{mol} / \mathrm{g} / \mathrm{h})\end{array}$ \\
\hline Siderophore ${ }^{\mathrm{a}}$ & Temperature $\left({ }^{\circ} \mathrm{C}\right)$ & $\mathrm{Y}=(0.067 \pm 0.012) \mathrm{X}+(6.6 \pm 2.6)^{\mathrm{c}}$ & $0.135 \pm 0.024^{\mathrm{c}}$ \\
DFO-B & 25 & $\mathrm{Y}=(0.117 \pm 0.022) \mathrm{X}+(9.7 \pm 4.6)$ & $0.234 \pm 0.044$ \\
& 40 & $\mathrm{Y}=(0.119 \pm 0.022) \mathrm{X}+(0.4 \pm 4.4)$ & $1.191 \pm 0.222$ \\
DFO-D1 & 55 & $\mathrm{Y}=(0.165 \pm 0.030) \mathrm{X}+(1.6 \pm 6.6)$ & $0.330 \pm 0.060$ \\
& 25 & $\mathrm{Y}=(0.251 \pm 0.013) \mathrm{X}+(10.7 \pm 2.8)$ & $0.503 \pm 0.026$ \\
& 40 & $\mathrm{Y}=(0.108 \pm 0.015) \mathrm{X}+(2.4 \pm 3.1)$ & $1.084 \pm 0.156$ \\
\hline
\end{tabular}

\footnotetext{
${ }^{\mathrm{a}}$ Initial siderophore concentration $=240 \mu \mathrm{M}$.

${ }^{\mathrm{b}} \mathrm{Y}=$ soluble $\mathrm{Fe}(\mu \mathrm{M}), \mathrm{X}=$ time $(\mathrm{h})$

${ }^{\mathrm{c}}$ Value $\pm 95 \%$ confidence interval $(p=0.05)$
}

erophore concentrations after equilibration ranged from 176 to $274 \mu \mathrm{M}$, all of which should be sufficient for maximal adsorption at pH 6.5 (Kraemer et al., 1999). For DFO-B, there was no significant change in surface excess as the temperature was increased from 25 to $55^{\circ} \mathrm{C}$, whereas for DFO-D1, a small increase occurred between 25 and $40^{\circ} \mathrm{C}$.

Stumm et al. (1987) have proposed that ligand-promoted mineral dissolution kinetics far from equilibrium can be characterized by a pseudo-first-order rate coefficient obtained as the ratio of the mass-normalized (or surface area-normalized) dissolution rate coefficient to the surface excess of the ligand promoting dissolution $\left(\mathrm{h}^{-1}\right)$. For example, Holmén and Casey (1998) calculated a pseudo-first-order rate coefficient equal to $0.073 \mathrm{~h}^{-1}$ on the basis of their dissolution rate data for goethite at $25^{\circ} \mathrm{C}$ in the presence of $10 \mathrm{mM}$ aHA at $\mathrm{pH} 4.5$ to 9 (fig. 5 in Holmén and Casey, 1996) combined with their adsorption edge data for aHA on goethite (fig. 7a in Holmén and Casey, 1996) obtained over the same $\mathrm{pH}$ range, but with varying total aHA concentration ( 0.1 to $1 \mathrm{mM}$ aHA). In the present study, we have combined the dissolution rate data in Table 1 with the surface excess data in Table 2 to calculate a pseudo-first-order rate coefficient for dissolution (column 4 of Table 2). Although the $\mathrm{pH}$ and total siderophore concentration for the two data sets are comparable, the solids concentrations differed substantially. Thus, we assume that this difference does not affect the surface excess significantly.

At 25 and $40^{\circ} \mathrm{C}$, the pseudo-first-order rate coefficient is the same for both siderophores, within experimental precision, and is independent of temperature. The pseudo-first-order rate coefficient that can be calculated with the dissolution rate and adsorption data of Kraemer et al. (1999) for DFO-D1 at $25^{\circ} \mathrm{C}$ $\left(0.05 \mathrm{~h}^{-1}\right)$ is consistent with the results in Table 2 , but that reported for DFO-B is much lower $\left(0.01 \mathrm{~h}^{-1}\right)$. The data obtained in the present study suggest that, in the temperature range 25 to $40^{\circ} \mathrm{C}$, the pseudo-first-order rate coefficient for the dissolution of goethite promoted by the two trihydroxamate siderophores has a temperature dependence that is essentially the same as that of adsorption. At $55^{\circ} \mathrm{C}$, however, the pseudofirst-order rate coefficient increases markedly and is no longer the same for the two siderophores, that for DFO-D1 falling to half the value for DFO-B. Therefore, surface excess, as measured in our experiments, was not the sole determinant of the temperature dependence of the rate of goethite dissolution promoted by the siderophores. This finding complements the suite of results at fixed temperature, in which proportionality exists between a ligand-promoted dissolution rate and a ligand surface excess (see, e.g., Stumm and Furrer, 1987).

\section{DISCUSSION}

The data in Tables 1 and 2 indicate that at $\mathrm{pH}$ 6.5, DFO-D1 adsorbs more strongly and promotes dissolution more effectively than DFO-B at 25 and $40^{\circ} \mathrm{C}$, an effect also noted by Kraemer et al. (1999) at the lower temperature. This difference was attributed by them to electrostatic repulsion of the cationic DFO-B $\left(\mathrm{pK}_{\mathrm{a}} \approx 8.5\right.$; see row 1 in Table 3 ) by the positively charged goethite surface at $\mathrm{pH} 6.5$ (p.z.n.p.c. $=8.1\left[25^{\circ} \mathrm{C}\right], 8.3$

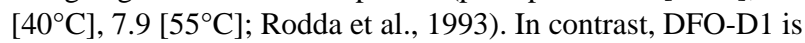
a neutral species and therefore would not be repelled from the goethite surface.

Table 2. Surface excess values for DFO-B and DFO-D1, together with the associated pseudo-first-order rate coefficients for goethite dissolution (pH 6.5).

\begin{tabular}{lccc}
\hline & & & $\begin{array}{c}\text { Pseudo-first-order } \\
\text { rate coefficient } \\
\left(\mathrm{h}^{-1}\right)\end{array}$ \\
\hline Siderophore $^{\mathrm{a}}$ & Temperature $\left({ }^{\circ} \mathrm{C}\right)$ & Surface excess $(\mu \mathrm{mol} / \mathrm{g})$ & $0.05 \pm 0.01^{\mathrm{b}}$ \\
DFO-B & 25 & $2.99 \pm 0.37^{\mathrm{b}}$ & $0.07 \pm 0.01$ \\
& 40 & $3.18 \pm 0.09$ & $0.33 \pm 0.07$ \\
DFO-D1 & 55 & $3.64 \pm 0.47$ & $0.06 \pm 0.01$ \\
& 25 & $5.49 \pm 0.19$ & $0.07 \pm 0.01$ \\
& 40 & $7.15 \pm 0.71$ & $0.16 \pm 0.03$ \\
\hline
\end{tabular}

\footnotetext{
${ }^{\mathrm{a}}$ Initial siderophore concentration $=300 \mu \mathrm{M}$.

${ }^{\mathrm{b}}$ Measured value \pm standard deviation.
} 
Table 3. Thermodynamics and kinetics data for the complexation reactions of desferrioxamine B [denoted (DFO-B) ${ }^{3-}$ ] and acetohydroxamate (denoted $\mathrm{aA}^{-}$) in aqueous solution.

\begin{tabular}{|c|c|c|c|}
\hline Reaction & $\log \mathrm{K}$ & $\log k_{\mathrm{f}}$ & $\log \mathrm{k}_{\mathrm{b}}$ \\
\hline $\mathrm{H}_{3}(\mathrm{HDFO}-\mathrm{B})^{+}=\mathrm{H}_{2}(\mathrm{HDFO}-\mathrm{B})^{0}+\mathrm{H}^{+}$ & $-8.51^{\mathrm{a}}$ & - & - \\
\hline $\mathrm{H}_{2}(\mathrm{HDFO}-\mathrm{B})^{0}=\mathrm{H}(\mathrm{HDFO}-\mathrm{B})^{-}+\mathrm{H}^{+}$ & $-8.73^{\mathrm{a}}$ & - & - \\
\hline $\mathrm{H}(\mathrm{HDFO}-\mathrm{B})^{-}=(\mathrm{HDFO}-\mathrm{B})^{2-}+\mathrm{H}^{+}$ & $-8.99^{\mathrm{a}}$ & - & - \\
\hline$(\mathrm{HDFO}-\mathrm{B})^{2-}=(\mathrm{DFO}-\mathrm{B})^{3-}+\mathrm{H}^{+}$ & $-10.01^{\mathrm{a}}$ & - & - \\
\hline $\mathrm{H}_{3}(\mathrm{HDFO}-\mathrm{B})^{+}+\mathrm{Fe}^{3+} \Leftrightarrow \Leftrightarrow_{\mathrm{k}}^{\mathrm{k}_{\mathrm{f}}} \mathrm{FeH}_{2}(\mathrm{HDFO}-\mathrm{B})^{3+}+\mathrm{H}^{+}$ & $3.60^{\mathrm{b}}$ & 0.30 & -3.30 \\
\hline $\mathrm{FeH}_{2}(\mathrm{HDFO}-\mathrm{B})^{3+} \Leftrightarrow \mathrm{FeH}(\mathrm{HDFO}-\mathrm{B})^{2+}+\mathrm{H}^{+}$ & $-0.72^{\mathrm{b}}$ & -1.36 & -0.64 \\
\hline $\mathrm{FeH}(\mathrm{HDFO}-\mathrm{B})^{2+} \Leftrightarrow \mathrm{Fe}(\mathrm{HDFO}-\mathrm{B})^{+}+\mathrm{H}^{+}$ & $-0.58^{\mathrm{b}}$ & 2.00 & 2.58 \\
\hline $\mathrm{aHA}^{0}=\mathrm{aA}^{-}+\mathrm{H}^{+}$ & $-8.89^{\mathrm{c}}$ & - & - \\
\hline \multirow{2}{*}{\multicolumn{4}{|c|}{$\mathrm{aHA}^{0}+\mathrm{Fe}^{3+} \Leftrightarrow \mathrm{FeaA}^{2+}+\mathrm{H}^{+}$}} \\
\hline & & & \\
\hline \multicolumn{4}{|l|}{$\mathrm{k}_{\mathrm{b}}$} \\
\hline $\mathrm{FeaA}^{2+}+\mathrm{aHA}^{0} \Leftrightarrow \mathrm{Fe}(\mathrm{aA})_{2}^{+}+\mathrm{H}^{+}$ & $-0.18^{\mathrm{c}}$ & 3.16 & 3.34 \\
\hline 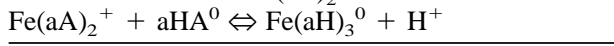 & $-1.79^{\mathrm{c}}$ & 3.18 & 4.97 \\
\hline
\end{tabular}

\footnotetext{
${ }^{a}$ Thermodynamics data at $298 \mathrm{~K}$ from Borgias et al. (1989). The $\mathrm{H}$ enclosed in parentheses is that on the amine group of the siderophore. The other $\mathrm{H}$ are on the hydroxamate groups (Fig. 1).

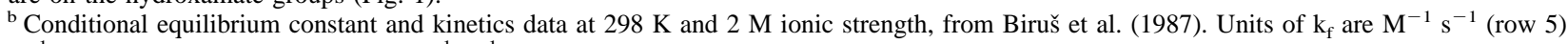
or $\mathrm{s}^{-1}$ (rows 6 and 7). Units of $\mathrm{k}_{\mathrm{b}}$ are $\mathrm{M}^{-1} \mathrm{~s}^{-1}$. $\mathrm{k}_{\mathrm{f}}$ and $\mathrm{k}_{\mathrm{b}}$ are forward and backward rate coefficients, respectively.

${ }^{\mathrm{c}}$ Conditional equilibrium constant and kinetics data at $298 \mathrm{~K}$ and $2 \mathrm{M}$ ionic strength, from Biruš et al. (1985). Units of $\mathrm{k}_{\mathrm{f}}$ and $\mathrm{k}_{\mathrm{b}}$ are $\mathrm{M}^{-1} \mathrm{~s}^{-1}$. Ionic strength is $1 \mathrm{M}$ for the reaction in row 8 .
}

Holmén and Casey (1996) have outlined a mechanism for goethite dissolution promoted by the monohydroxamate ligand, aHA. Noting that both hydrophobicity and significant conformational changes attend the surface complexation reactions of large biomolecules, such as DFO-B, Holmén and Casey (1996) speculated that only one or two hydroxamate groups in the siderophore might be able to coordinate to reactive $\mathrm{Fe}$ (III) centers at the mineral surface. Indeed, the general concordance, noted above, among the pseudo-first-order rate coefficients for goethite dissolution measured at $25^{\circ} \mathrm{C}$ in the presence of aHA, DFO-B, and DFO-D1 suggests that coordination of just one $\mathrm{Fe}(\mathrm{III})$ center at the mineral surface by the siderophores may be occurring.

This hypothesis can be examined in the light of available estimates of thermodynamic and kinetics data for the complexation of $\mathrm{Fe}^{3+}$ in aqueous solution by DFO-B and aHA, some of which are compiled in Table 3. Coordination of $\mathrm{Fe}^{3+}$ by the hydroxamate group farthest from the protonated amine in DFO-B (Fig. 1) is highly favored over subsequent coordination by a second or third hydroxamate group closer to the positive charge site (row 5 vs. rows 6 and 7 in Table 3). Indeed, the log $\mathrm{K}$ data (column 2) indicate an increase in the standard Gibbs energy change for the complexation reaction as a result of coordination to more than one hydroxamate group, with a concomitant increase in the kinetic lability of the complex formed (i.e., increasing $\mathrm{k}_{\mathrm{b}}$, column 4). The same trend is observed for the coordination of more than one aHA ligand to $\mathrm{Fe}^{3+}$ (row 9 vs. rows 10 and 11 in Table 3). Therefore, in aqueous solution, coordination of $\mathrm{Fe}^{3+}$ by a single hydroxamate group is a favored process, even though the siderophore complex involves hexadentate ligation with three hydroxamate groups (Crumbliss, 1991).

One possible cause of the more facile proton-assisted removal of hydroxamate groups in Fe-aA complexes as compared with Fe-DFO-B complexes (i.e., the larger $k_{b}$ values for the Fe-aA complexes in column 4 of Table 3 as compared with the Fe-DFO-B complexes) is the hydrophobic backbone in DFO-B (Fig. 1), which could prevent easy access of the proton to a site of $\mathrm{Fe}^{3+}$ coordination (Biruš et al., 1987). Another possible cause of the difference in complex stability between the siderophore and the simple hydroxamate ligand is the difference in substituent on the $\mathrm{N}$ atom in the coordinating hydroxamate (i.e., an alkyl group vs. a proton), which places additional electron density on the carbonyl $\mathrm{O}$ in the case of the siderophore (Crumbliss, 1991). These effects notwithstanding, a strong consensus exists in the literature for similarity in the complexation of $\mathrm{Fe}^{3+}$ by DFO-B and simple monohydroxamates (Biruš et al., 1988; Crumbliss, 1991). We believe that this consensus lends support to the hypothesis that DFO-B adsorbs on the goethite surface by use of a single hydroxamate group, as described by Holmén and Casey (1996) for aHA (their fig. 11). The same reasoning would apply to DFO-D1.

Indirect evidence for a surface complexation mechanism involving a single hydroxamate group can be adduced through an analysis of the temperature dependence of the mass-normalized dissolution rate coefficients in Table 1 via the Arrhenius equation (Lasaga, 1998),

$$
\mathrm{k}=\mathrm{A} \exp \left(-\mathrm{E}_{\mathrm{a}} / \mathrm{RT}\right)
$$

where $\mathrm{A}$ is a preexponential factor, $\mathrm{E}_{\mathrm{a}}$ is an apparent activation energy, $\mathrm{R}$ is the gas constant, and $\mathrm{T}$ is absolute temperature. Lasaga (1998) has discussed the application of Eqn. 1 to rate coefficients for the proton-promoted dissolution of a wide variety of minerals. He notes that the parameters $A$ and $E_{a}$ reported for many minerals are positively correlated according to a "compensation law,"

$$
\ln \mathrm{A}=\mathrm{a}+\alpha\left(\mathrm{E}_{\mathrm{a}} / \mathrm{R}\right)
$$

where a is a parameter whose value depends on the units in which $\mathrm{k}$ in Eqn. 1 is expressed and $\alpha$ is a parameter expressing 
Table 4. Adjustable parameter values for the Arrhenius equation with a compensation law (Eqn. 3) ${ }^{\mathrm{a}}$

\begin{tabular}{lccc}
\hline Siderophore & $\mathrm{T}(\mathrm{K})$ & $\alpha\left(10^{-3} \mathrm{~K}^{-1}\right)$ & $\mathrm{E}_{\mathrm{a}}(\mathrm{kJ} / \mathrm{mol})$ \\
\hline DFO-B & 298 & 2.27 & 28.5 \\
DFO-B & 313 & 2.27 & 28.5 \\
DFO-B & 328 & 2.60 & 28.5 \\
DFO-D1 & 298 & 2.27 & 21.7 \\
DFO-D1 & 313 & 2.27 & 21.7 \\
DFO-D1 & 328 & 2.42 & 21.7 \\
\hline
\end{tabular}

${ }^{a}$ The value of the parameter a in Eqn. 3 is 1.72 for both siderophores at all three temperatures.

the positive correlation. With this relationship between A and $\mathrm{E}_{\mathrm{a}}$, Eqn. 1 takes the form

$$
\mathrm{k}=\exp (\mathrm{a}) \exp \left[\left(\alpha-\frac{1}{\mathrm{~T}}\right) \frac{\mathrm{E}_{\mathrm{a}}}{\mathrm{R}}\right]
$$

Lasaga (1998) has discussed Eqn. 2 in the context of the transition state theory of reaction rates, noting that a positive linear correlation between the entropy and the enthalpy of activation is implied by Eqn. 2, such that increases in $\mathrm{E}_{\mathrm{a}}$ ("barrier height") are compensated by increases in A ("frequency factor"). If the two thermodynamic parameters obey the linear relationship,

$$
\Delta \mathrm{S}^{\ddagger}=\alpha \Delta \mathrm{H}^{\ddagger}+\beta
$$

where $\mathrm{S}$ is entropy and $\mathrm{H}$ is enthalpy, then $\mathrm{A}$ and $\mathrm{E}_{\mathrm{a}}$ are correspondingly related by the equation (Lasaga, 1998),

$$
\ln \mathrm{A}=\text { constant }+\alpha\left(\mathrm{E}_{\mathrm{a}} / \mathrm{R}\right)
$$

which is identical in form to the compensation law in Eqn. 2. The meaning of $\alpha$ is the same in each expression. However, Laidler (1987) cautions against a strictly kinetics interpretation of the parameter $\alpha$ in Eqn. 4 because "compensation" between $\Delta \mathrm{S}^{\ddagger}$ and $\Delta \mathrm{H}^{\ddagger}$ is also expected solely from solvent interactions with the reactants that combine to form the activated complex. For example, if $\Delta \mathrm{H}^{\ddagger}$ decreases because of strong solvent interactions, so will $\Delta \mathrm{S}^{\ddagger}$ in reflecting the loss of motional freedom of solvating water molecules.

An application of Eqn. 3 is reported in Table 4. The values of the parameters $\mathrm{a}, \alpha$, and $\mathrm{E}_{\mathrm{a}}$ were first determined by applying Eqns. 1 and 2 at 25 and $40^{\circ} \mathrm{C}$. Then only the parameter $\alpha$ was adjusted to fit the data at $55^{\circ} \mathrm{C}$ while the values of a and $\mathrm{E}_{\mathrm{a}}$ remained fixed. This procedure, followed solely for the sake of simplicity, gave values of the three adjustable parameters that yielded an excellent fit of the Arrhenius equation to the massnormalized rate coefficient data in Table 1 . Note that the prefactor, $\exp (\mathrm{a})$, turned out to have the same value $(5.6 \mu \mathrm{mol} /$ $\mathrm{g} / \mathrm{h}$ ) for both siderophores, but the apparent activation energy is somewhat larger for DFO-B than DFO-D1, as expected because of repulsion between the goethite surface and the former siderophore. The parameter $\alpha$ turned out to be the same for both siderophores at 25 and $40^{\circ} \mathrm{C}$, but increased somewhat for both at $55^{\circ} \mathrm{C}$. The two values of $\mathrm{E}_{\mathrm{a}}$ in Table 4 are much smaller than those reported for the proton-promoted dissolution of goethite and other minerals (Wieland et al., 1988; Casey and Sposito, 1992; Cornell and Schwertmann, 1996; Lasaga, 1998).
Biruš et al. (1988) have shown that the compensation law in Eqn. 4 applies to the activation thermodynamics parameters for the reaction in which $\mathrm{Fe}^{3+}$ coordinates to a single hydroxamate group, either in DFO-B or in a variety of monohydroxamates. Their "isokinetic plot" (Fig. 1B in their article) can be modeled by the explicit mathematical form

$$
\Delta \mathrm{S}^{\ddagger}=2.74 \times 10^{-3} \Delta \mathrm{H}^{\ddagger}-206
$$

with $\Delta \mathrm{S}^{\ddagger}$ in units of $\mathrm{J} / \mathrm{mol} / \mathrm{K}$ and $\Delta \mathrm{H}^{\ddagger}$ in units of $\mathrm{J} / \mathrm{mol}$. There is a striking similarity between the coefficient of $\Delta \mathrm{H}^{\ddagger}$ in Eqn. 6 and the values of $\alpha$ listed in Table 4. Biruš et al. (1988) concluded from the conformity of both DFO-B and monohydroxamate ligands to the same relation between $\Delta \mathrm{S}^{\ddagger}$ and $\Delta \mathrm{H}^{\ddagger}$ that a common reaction mechanism exists among these compounds in their coordination to $\mathrm{Fe}^{3+}$ in aqueous solution. The close correspondence of the values of $\alpha$ in Eqn. 6 and Table 4 leads us to speculate that DFO-B and aHA also may dissolve goethite by similar mechanisms. As noted by Holmén and Casey (1996) and seconded by Kalinowski et al. (2000), this mechanism, surprisingly, is not particularly effective at releasing $\mathrm{Fe}$ from goethite when compared with other common biologic ligands, such as oxalate.

Acknowledgments-Research was supported in part by the Director, Office of Energy Research, Office of Basic Energy Sciences, Geosciences Program, U.S. Department of Energy (grant DE-FG0396ER 14667), and in part by funds provided by the University of California for the conduct of discretionary research by Los Alamos National Laboratory (UCDRD Program). Gratitude is expressed to three anonymous referees for helpful reviews; to Jide Xu for preparation of the sample of DFO-D1; to Rita Zapf for development of the method for siderophore quantitation; and to Angela Zabel for excellent preparation of the typescript.

Associate editor: S. J. Traina

\section{REFERENCES}

Albrecht-Gary A.-M. and Crumbliss A. L. (1998) Coordination chemistry of siderophores: Thermodynamics and kinetics of iron chelation and release. Metal Ions Biol. Sys. 35, 239-237.

Biruš M., Bradić Z., Kujundžić N., Pribanić M., Wilkins P. C., and Wilkins R. G. (1985) Stopped-flow and rapid-scan spectral examination of the iron(III)-acethydroxamic acid system. Inorg. Chem. 24, 2980-2983.

Biruš M., Bradić Z., Krznarić G., Kujundžić N., Pribanić M., Wilkins P. C., and Wilkins R. G. (1987) Kinetics of stepwise hydrolysis of ferrioxamine B and formation of diferrioxamine B in acid perchlorate solution. Inorg. Chem. 26, 1000-1005.

Biruš M., Krznarić G., Kujundžaić N., and Pribanić M. (1988) Kinetic and equilibrium thermodynamic description of the interaction of desferrioxamine B and acethydroxamic acid with iron(III) in acid aqueous perchlorate. Croat. Chem. Acta 61, 33-39.

Borgias B., Hugi A. D., and Raymond K. N. (1989) Isomerization and solution structures of desferrioxamine $\mathrm{B}$ complexes of $\mathrm{Al}^{3+}$ and $\mathrm{Ga}^{3+}$. Inorg. Chem. 28, 3538-3545.

Brantley S. L. and Chen Y. (1995) Chemical weathering rates of pyroxenes and amphiboles. Rev. Mineral. 31, 119-172.

Casey W. H. and Sposito G. (1992) On the temperature dependence of mineral dissolution rates. Geochim. Cosmochim. Acta 56, 38253830.

Cornell R. M. and Schwertmann U. (1996) The Iron Oxides. VCH.

Crumbliss A. (1991) Aqueous solution equilibrium and kinetic studies of iron siderophore and model siderophore complexes. In Handbook of Microbial Iron Chelates(ed. G. Winkelmann), pp. 177-232. CRC Press.

Eick M. J., Peak J. D., and Brady W. D. (1999) The effect of oxyanions 
on the oxalate-promoted dissolution of goethite. Soil Sci. Soc. Am. J. 63, 1133-1141.

Holmén B. A. and Casey W. H. (1996) Hydroxamate ligands, surface chemistry, and the mechanism of ligand-promoted dissolution of goethite $[\alpha-\mathrm{FeOOH}(\mathrm{s})]$. Geochim. Cosmochim. Acta 60, 4403-4416.

Holmén B. A., Tejedor-Tejedor M. I., and Casey W. H. (1997) Hydroxamate complexes in solution and at the goethite-water interface: A cylindrical internal reflection Fourier transform infrared spectroscopy study. Langmuir 13, 2197-2206.

Holmén B. A. and Casey W. H. (1998) Erratum to Hydroxamate ligands, surface chemistry, and the mechanism of ligand-promoted dissolution of goethite $[\alpha-\mathrm{FeOOH}(\mathrm{s})]$. Geochim. Cosmochim. Acta 62, 726.

Kalinowski B. E., Liermann L. J., Givens S., and Brantley S. L. (2000) Rates of bacteria-promoted solubilization of Fe from minerals: A review of problems and approaches. Chem. Geol. 169, 357-370.

Kraemer S. M., Cheah S.-F., Zapf R., Xu J., Raymond K., and Sposito G. (1999) Effect of hydroxamate siderophores on Fe release and $\mathrm{Pb}$ (II) adsorption by goethite. Geochem. Cosmochem. Acta 63, 3003-3008.

Laidler K. J. (1987) Chemical Kinetics. Harper and Row.

Lasaga A. C. (1998) Kinetic Theory in the Earth Sciences. Princeton University Press.

Liermann L. J., Kalinowski B. E., Brantley S. L., and Ferry J. G. (2000) Role of bacterial siderophores in dissolution of hornblende. Geochim. Cosmochim. Acta 64, 587-602.

Rodda D. P., Johnson B. B., and Wells J. D. (1993) The effect of temperature and $\mathrm{pH}$ on the adsorption of copper(I), lead(II), and zinc(II) onto goethite. J. Colloid Interface Sci. 161, 57-62.
Schwertmann U. and Cornell R. M. (1991) Iron Oxides in the Laboratory. $\mathrm{VCH}$.

Solinas V. (1994) Cation effects on the adsorption of deferrioxamine B (DFOB) by humic acid. In Humic Substances in the Global Environment and Implications on Human Health(eds. N. Senesi and T. M. Miano), pp. 1183-1188. Elsevier Science.

Sposito G. (1994) Chemical Equilibria and Kinetics in Soils. Oxford University Press.

Stumm W. and Furrer G. (1987) The dissolution of oxides and aluminum silicates; examples of surface-controlled kinetics. In Aquatic Surface Chemistry (ed. W. Stumm), pp. 197-219. Wiley-Interscience.

Stumm W., Wehrli B., and Wieland E. (1987) Surface complexation and its impact on geochemical kinetics. Croat. Chem. Acta 50, $1861-1869$

van der Helm D., Jalal M. A. F., and Hossain M. B. (1987) The crystal structures, conformations, and configurations of siderophores. In Iron Transport in Microbes, Plants and Animals (eds. G. Winkelmann, D. van der Helm, and J. B. Neilands), pp. 135-165. VCH.

Wieland E., Wehrli B., and Stumm W. (1988) The coordination chemistry of weathering: III. A generalization on the dissolution rates of minerals. Geochim. Cosmochim. Acta 52, 1969-1981.

Yu Q., Kandegedara A., Xu Y., and Rorabacher D. B. (1997) Avoiding interferences from Good's buffers: A contiguous series of noncomplexing tertiary amine buffers covering the entire range of $\mathrm{pH} 3-11$. Anal. Biochem. 253, 50-56.

Zinder B, Furrer G., and Stumm W. (1986) The coordination chemistry of weathering: II. Dissolution of Fe(III) oxides. Geochim. Cosmochim. Acta 50, 1861-1869. 